07

\title{
Влияние слоя аморфного кремния на адсорбционные свойства полупроводниковой структуры в условиях фотостимуляции
}

\author{
() С.В. Стецюра ${ }^{1}$, А.В. Козловский ${ }^{1}$, Д.М. Митин ${ }^{2}$, А.А. Сердобинцев ${ }^{1}$ \\ ${ }^{1}$ Саратовский национальный исследовательский государственный университет им. Н.Г. Чернышевского, Саратов, Россия \\ ${ }^{2}$ Физико-технический институт им. А.Ф. Иофрфе РАН, Санкт-Петербург, Россия \\ E-mail: Stetsyurasv@mail.ru
}

Поступило в Редакцию 10 сентября 2018 г.

Изучена фотостимулированная адсорбция глюкозооксидазы (GOx) на пластины монокристаллического $\mathrm{Si}$ с покрытием из аморфного $\mathrm{Si}(a-\mathrm{Si})$. Оценка разности заполнения поверхности молекулами GOx при фотостимулированной адсорбции и темновой адсорбции позволила установить, что этот показатель увеличивается для структур, содержащих слой $a$-Si, в 2.5 раза при использовании $n$-Si и в 1.5 раза в случае $p$-Si. Показано, что в структуре $n$ - $\mathrm{Si} / a$-Si возможна реализация метода предварительной фотостимуляции процесса адсорбции GOx.

DOI: 10.21883/PJTF.2019.02.47215.17520

Ранее в работах [1,2] было показано, что при использовании фоточувствительного полупроводника в качестве подложки при адсорбции полиэлектролитов из раствора можно эффективно управлять характеристиками получаемой гибридной структуры, освещая подложку в процессе адсорбции. Изменяющийся при освещении поверхностный потенциал позволял в зависимости от типа проводимости $\mathrm{Si}$ увеличить или уменьшить электростатическое взаимодействие молекул подложки и полиэлектролита, что приводило к изменению как электрофизических характеристик гибридной структуры в целом, так и свойств полиэлектролитного слоя [1]. В частности, было показано, что фотостимулированная адсорбция (ФСА) глюкозооксидазы (GOx) на поверхность структуры $n$ - $\mathrm{Si} / \mathrm{SiO}_{2} /$ полиэтиленимин (ПЭИ) позволяет увеличить плотность иммобилизованных молекул GOx в 7 раз на освещаемом участке подложки по сравнению с таковой на затемненном. На поверхности $p-\mathrm{Si} / \mathrm{SiO}_{2} /$ ПЭИ плотность GOx уменьшалась в 3 раза при освещении подложки во время адсорбции GOx белым светом с интенсивностью $2.2 \cdot 10^{4} \mathrm{~lx}$ [3].

Но попытки получить локальное изменение адсорбционных свойств при облучении лазерным лучом участка поверхности микронной площади потерпели неудачу изза „растекания“ неравновесных носителей заряда (ННЗ) за счет их диффузии в $\mathrm{Si}$ и рассеяния светового луча раствором GOx. Первая проблема может быть решена за счет резкого увеличения ловушек для НН3 на границах освещаемых участков, что должно привести к накоплению и стабилизации заряда только на этих участках. Вторая проблема решается за счет освещения и формирования участков с измененными адсорбционными свойствами еще до адсорбции GOx при условии наличия долговременной релаксации поверхностного потенциала после освещения полупроводниковой подложки.

Для практической реализации этих условий нами была использована структура, состоящая из пластины монокристаллического $\mathrm{Si}(c-\mathrm{Si})$ с нанометровым покры- тием из аморфного $\mathrm{Si}(a-\mathrm{Si})$. При этом принимались во внимание следующие свойства $a$-Si. Во-первых, его успешно используют в качестве основы для структур различных датчиков, в том числе биосенсоров [4], поскольку его адсорбирующие свойства, как правило, выше, чем у $c$-Si [5]. Во-вторых, оптическое поглощение $a-\mathrm{Si}$ в видимой области в 20 раз выше, чем у $c$-Si $[6,7]$, поэтому для существенного поглощения видимого света достаточно пленки $a-\mathrm{Si}$ толщиной $100-500 \mathrm{~nm}$. Кроме того, такие свойства $a-\mathrm{Si}$, как низкая подвижность носителей заряда, большая плотность центров захвата для носителей заряда различного типа, высокая скорость рекомбинации НН3 $[8,9]$ и как следствие высокое темновое сопротивление, позволяют создавать покрытия с высоким латеральным разрешением, чувствительные к воздействию внешних полей, в частности оптического излучения. Но указанные выше свойства $a$-Si приводят также к низкой фоточувствительности [10]. Поэтому использование структуры $c$-Si с покрытием из $a$-Si нанометровой толщины, обеспечивающей генерацию ННЗ в $c$-Si и эффективное разделение их на границе гетероперехода $c-\mathrm{Si} / a-\mathrm{Si}$, представляется перспективным для обеспечения одновременно высокой фоточувствительности и субмикронного разрешения, достигаемого при модификации поверхностного потенциала подложки лазерным лучом.

Целью настоящей работы является экспериментальное и теоретическое обоснование типа проводимости $c$ - $\mathrm{Si}$, позволяющего в сочетании с тонкой пленкой $a-\mathrm{Si}$ $n$-типа обеспечить эффективное управление адсорбционными свойствами структуры $c-\mathrm{Si} / a-\mathrm{Si}$ при освещении длинами волн из области поглощения $c-\mathrm{Si}$.

В исследовании использовались подложки $c$-Si кристаллографической ориентации (100) n- и $p$-типов проводимости с удельным сопротивлением $4 \Omega \cdot \mathrm{cm}$, на которых формировался слой $a-\mathrm{Si}$ толщиной $100 \mathrm{~nm} \mathrm{c}$ удельным сопротивлением $1 \cdot 10^{8} \Omega \cdot \mathrm{cm}$ и шероховатостью поверхности $0.1 \mathrm{~nm}$. Пленки $a-\mathrm{Si}$ были получе- 
Изменение заполнения поверхности подложки молекулами GOx при ФСA

\begin{tabular}{c|c|c|c}
\hline Структура & $S_{\text {dark }}, \%$ & $S_{i l l}, \%$ & $\delta, \%$ \\
\hline$n-\mathrm{Si} / a-\mathrm{Si} / \Pi Э И / \mathrm{GOx}$ & 3.31 & 7.99 & +141.39 \\
$n-\mathrm{Si} / \Pi Э И / \mathrm{GOx}$ & 2.32 & 4.23 & +82.33 \\
$p-\mathrm{Si} / a-\mathrm{Si} / \Pi Э И / \mathrm{GOx}$ & 10.59 & 2.74 & -74.13 \\
$p-\mathrm{Si} / \Pi Э И / \mathrm{GOx}$ & 11.03 & 5.86 & -46.87
\end{tabular}

ны магнетронным распылением на постоянном токе при давлении рабочего газа (аргона) $1.5 \cdot 10^{-4}$ Torr и температуре подложки $150^{\circ} \mathrm{C}$ из дисковой мишени $n$ $\mathrm{Si}$ производства ООО „Гирмет“ (Россия) на установке Angstrom Nexdep (Angstrom Engineering, США). Выбор столь низкой величины давления рабочего газа, не характерной для метода магнетронного распыления, обусловлен ранее обнаруженными закономерностями получения $a-\mathrm{Si}[11]$. Полученные пленки $a-\mathrm{Si}[12]$ имели $n$-тип проводимости и довольно плотную однородную структуру.

Адсорбция фермента осуществлялась из водного раствора с концентрацией $\mathrm{GOx} 0.5 \mathrm{mg} / \mathrm{ml}$ в течение $10 \mathrm{~min}$. Перед иммобилизацией $\mathrm{GOx}$ на очищенные подложки наносился буферный слой ПЭИ для лучшего закрепления молекул фермента. Подложка очищалась в стандартном цикле жидкостной обработки, первой операцией которого являлась гидрофилизация поверхности в перекисно-аммиачном растворе $\left(\mathrm{NH}_{4} \mathrm{OH}: \mathrm{H}_{2} \mathrm{O}_{2}: \mathrm{H}_{2} \mathrm{O}=1: 1: 4\right.$ (vol.)) при $75^{\circ} \mathrm{C}$ в течение $10 \mathrm{~min}$. Гидрофилизация обеспечивает равномерное распределение слоя адсорбированной воды (отрицательно заряженных ОН-групп) на поверхности, что значительно повышает воспроизводимость дальнейших адсорбционных процессов. Кроме того, в результате такой обработки на поверхности образуется тонкая, не превышающая по толщине $2 \mathrm{~nm}$ пленка $\mathrm{SiO}_{2}$ [13]. Освещение подложки во время адсорбции GOx осуществлялось с помощью галогенной лампы Philips 13186 EPX/EPV с интенсивностью $2.2 \cdot 10^{4} 1 \mathrm{x}$ в плоскости подложки. Соблюдение технологического алгоритма позволило получать слои с воспроизводимыми параметрами, что контролировалось методом атомно-силовой микроскопии (ACM) на зондовой станции NTEGRA Spectra (НТ-МДТ Спектрум Инструментс, Россия).

Исследование ФСА фермента GOx проводилось на данных структурах впервые. Сравнение результатов, представленных на рис. 1 в настоящей работе и на рис. 1 в [3], позволяет утверждать, что качественно наличие слоя $a$-Si не меняет результат: плотность иммобилизованных молекул GOx увеличивается при ФСА по сравнению с полученной в случае темновой адсорбции на структуре $n-\mathrm{Si} / a-\mathrm{Si}$ и уменьшается при использовании $p$-Si $/ a-\mathrm{Si}$. При этом оценка относительного изменения $\delta$ - процента заполнения поверхности молекулами GOx - показала, что эффективность ФСА увеличивается на структурах, содержащих слой $a-\mathrm{Si}$ (см. таблицу). Значения $\delta$ рассчитывались по формуле $\delta=100\left(S_{i l l}-S_{d a r k}\right) / S_{d a r k}$, где $S_{i l l}$ и $S_{\text {dark }}$ - проценты заполнения поверхности молекулами GOx при ФСА и при адсорбции в темноте соответственно, которые определялись по АСМ-изображениям (рис. 1) в программе Gwyddion.

Время релаксации поверхностного потенциала $\varphi$ кремниевых подложек после выключения освещения оценивалось по изменению контактной разности потенциалов (КРП) методом зонда Кельвина с использованием сетчатого золотого электрода. КРП и ее изменения при включении и выключении света на исследуемых структурах показаны на рис. 2. Интенсивность освещения в плоскости образца при измерениях составляла $3 \cdot 10^{3} 1 \mathrm{x}$.

Из рис. 2, $a$ следует, что на структурах без слоя $a-\mathrm{Si}$ релаксация заряда происходит быстро и исходные значения $\varphi$ восстанавливаются практически „мгновенно“. Изменения $\varphi$ для структур $c-\mathrm{Si} / a-\mathrm{Si}$ (рис. $2, b)$, как это и следовало ожидать, более „затянуты“ и при включении, и при выключении света. Но при этом на зависимости, соответствующей структуре $p-\mathrm{Si} / a-\mathrm{Si}$, происходят сначала резкие „скачки“ $\varphi$ с последующим медленным уменьшением (рис. 2, $b$, область I) или увеличением (рис. $2, b$, область II). Для структур $n-\mathrm{Si} / a-\mathrm{Si}$ резкого скачка $\varphi$ не наблюдается, освещение непрерывно уменьшает $\varphi$ при включении света (рис. 2, $b$, область I), но через час после выключения света релаксация $\varphi$ составляет не более $50 \%$ от исходного значения, т.е. за $10-15 \mathrm{~min}$ (время, достаточное для проведения адсорбции GOx) $\varphi$ освещенной области релаксирует лишь на $15-16 \%$.

Различие релаксации $\varphi$ для структур $p-\mathrm{Si} / a-\mathrm{Si}$ и $n-\mathrm{Si} / a-\mathrm{Si}$ объясняется следующим образом. Освещение $a$-Si способствует разрыву связей $\mathrm{Si}-\mathrm{Si}$ и образованию новых оборванных связей (ОС). Известно [14], что в случае $a$-Si $n$-типа ОС находятся в двух зарядовых состояниях: нейтральном $\left(D^{0}\right)$ и отрицательно заряженном $\left(D^{-}\right)$. Показано [15], что в нейтральном состоянии ОС дают мелкие уровни, обладающие большим сечением захвата. При захвате электрона на $D^{0}$ за счет поляронного эффекта [16] и изменения области локализации валентных электронов атомов связи $\mathrm{Si}-\mathrm{Si}$ происходит сдвиг мелких уровней в глубь запрещенной зоны на $1.4-1.5 \mathrm{eV}$, что затрудняет тепловой выброс носителей заряда и значительно увеличивает время релаксации заряда. Но если часть ОС зарядится положительно, то велика вероятность образования комплексов близких ОС (КБОС). В [17] показано, что многофононная трехступенчатая рекомбинация, включающая туннельные переходы внутри КБОС, существенно более эффективна, чем двухступенчатая рекомбинация через изолированные ОС. Таким образом, наличие изолированных ОС приводит к долговременной релаксации фотопроводимости, а образование КБОС способствует достаточно быстрому возвращению $a-\mathrm{Si}$ к исходному состоянию. 
$a$

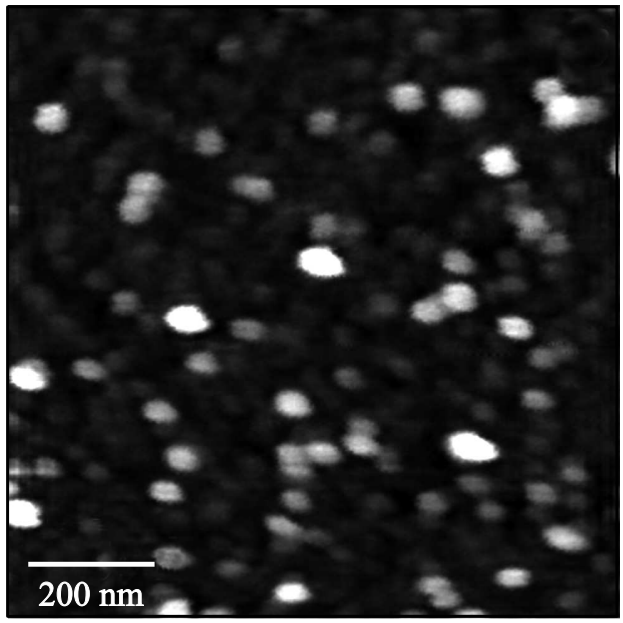

$c$

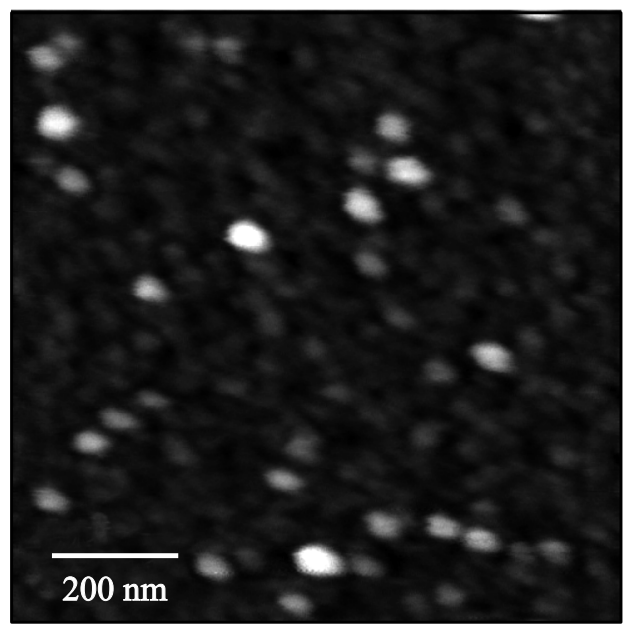

$b$
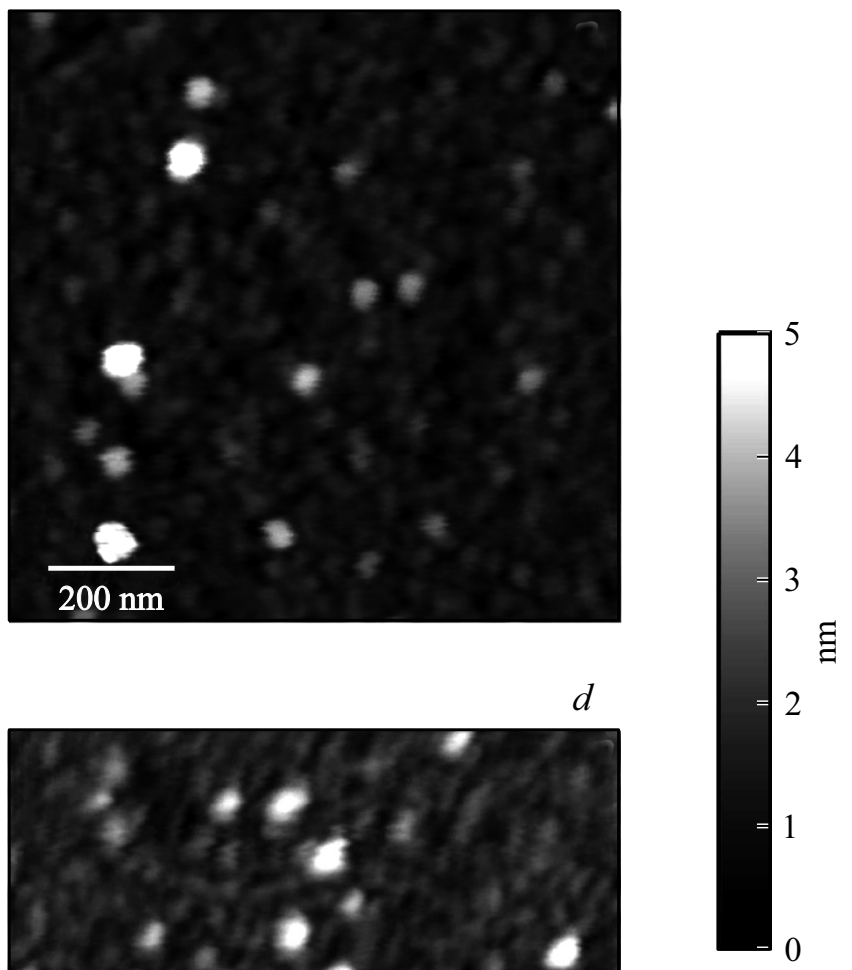

Рис. 1. АСМ-изображения структур $p$-Si/ $a$-Si/ПЭИ/GOx $(a, b)$ и $n$ - $\mathrm{Si} / a-\mathrm{Si} /$ ПЭИ/GOx $(c, d)$ после нанесения слоя молекул $\mathrm{GOx}$ в темноте $(a, c)$ и при освещении $(b, d)$ пластины $\mathrm{Si}$ во время адсорбции $\mathrm{GOx}$.
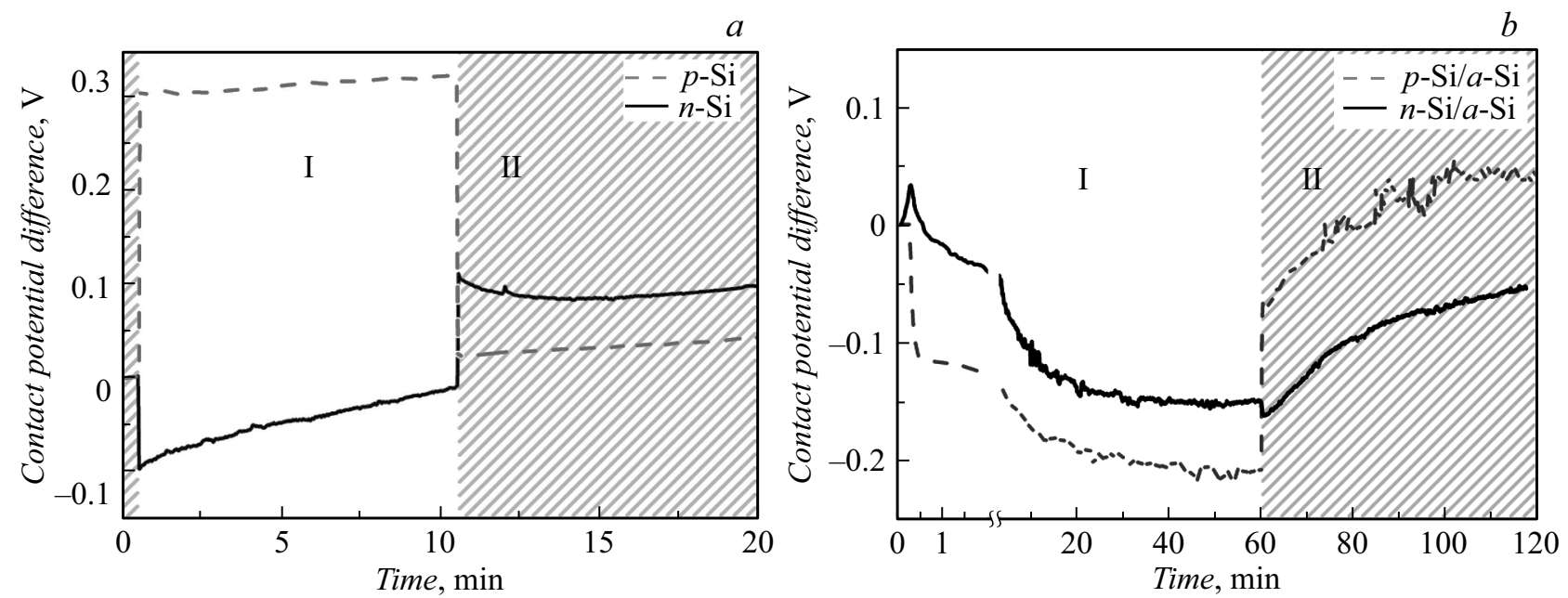

Рис. 2. Изменение КРП для структур на основе $\mathrm{Si} n$ - и $p$-типов без слоя $a$-Si $(a)$ и со слоем $a$-Si $(b)$ при включении (диапазон времени I) и выключении (диапазон времени II) освещения. 
При освещении исчезают или существенно уменьшаются область пространственного заряда и потенциальный барьер со стороны $c$-Si, и носители заряда, поступающие из освещенного $c-\mathrm{Si}$, диффундируют в $a-\mathrm{Si}$, способствуя перезарядке ОС. Для образования КБОС стадия захвата дырки является лимитирующей [18], поэтому в случае структуры $p$-Si/a-Si образование рекомбинационных центров идет быстрее и приводит к быстрой релаксации заряда. Для структуры $n-\mathrm{Si} / a-\mathrm{Si}$, напротив, наблюдается долговременная релаксация заряда благодаря увеличению количества изолированных ОС.

Таким образом, наличие $c$-Si $n$ - или $p$-типа под слоем $a-\mathrm{Si}$ способствует либо преобладающему существованию изолированных $\mathrm{OC}(n-\mathrm{Si})$, либо образованию их комплексов $(p-\mathrm{Si})$. В связи с этим только в структуре $n-\mathrm{Si} / a-\mathrm{Si}$ возможна реализация метода предварительной (до погружения в раствор) фотостимуляции адсорбции, в результате которой происходит перезарядка поверхностных электронных состояний, сохраняющаяся длительное время.

Исследования выполнены при поддержке РФФИ (проект № 16-08-00524_a).

\section{Список литературы}

[1] Стеиюра С.В., Козловский А.В., Маляр И.В. // Письма в ЖТФ. 2015. Т. 41. В. 4. C. 24-32.

[2] Malyar I.V., Gorin D.A., Santer S., Stetsyura S.V. // Langmuir. 2013. V. 29. N 52. P. $16058-16065$. DOI: $10.1021 / 1 \mathrm{a} 403838$ n

[3] Стецюра С.В., Козловский А.В. // Письма в ЖТФ. 2017. T. 43. B. 6. C. 15-22.

DOI: 10.21883/PJTF.2017.06.44399.16510

[4] Yoshinobu T., Schöning M.J., Finger F., Moritz W., Iwasaki H. // Sensors. 2004. V. 4. N 10. P. 163-169. DOI: $10.3390 / \mathrm{s} 41000163$

[5] Давыдов С.Ю., Трошин С.В. // ФТТ. 2008. Т. 50. В. 7. C. $1206-1210$.

[6] Чопра К., Дас С. Тонкопленочные солнечные элементы. М.: Мир, 1986. $435 \mathrm{c.}$

[7] Janotta A., Janssen R., Schmidt M., Graf T., Stutzmann M., Görgens L., Bergmaier A., Dollinger G., Hammerl C., Schreiber S., Stritzker B. // Phys. Rev. B. 2004. V. 69. N 11. P. 115206. DOI: 10.1103/PhysRevB.69.115206

[8] Голикова О.А. // УФН. 1989. Т. 158. № 4. С. 581-604.

[9] Мотт Н., Дэвис Э. Электронные процессы в некристаллических материалах. М.: Мир, 1982. Т. 1. 368 с.

[10] Бонч-Бруевич В.Л. // УФН. 1983. Т. 140. № 4. С. 583-637.

[11] Митин Д.М., Сердобинцев А.А. // Письма в ЖТФ. 2017. T. 43. B. 17. C. $78-85$.

DOI: $10.21883 /$ PJTF.2017.17.44950.16804

[12] Митин Д.М., Александров В.А., Скапцов А.А., Вениг С.Б., Сердобинцев А.А. // Поверхность. Рентгеновские, синхротронные и нейтронные исследования. 2015. № 6. С. 1-4.

[13] Ohmi T. // Semicond. Int. 1996. V. 19. N 8. P. 2957-2964.

[14] Cтрит Р., Бигельсен Д. Спектроскопия локализованных состояний // Физика гидрогенизированного аморфного кремния. М.: Мир, 1988. Т. 2. 247 с.
[15] Карпушина А.А., Сорокина А.Н., Грищенко В.А. // Письма в ЖЭТФ. 2016. Т. 103. В. 3. С. 189-193. DOI: $10.7868 / \mathrm{S} 0370274 \mathrm{X} 16030061$

[16] Gritsenko V.A., Perevalov T.V., Orlov O.M., Krasnikov G.Ya. // Appl. Phys. Lett. 2016. V. 109. N 6. P. 062904. DOI: $10.1063 / 1.4959830$

[17] Звягин И.П. // ФТП. 1993. Т. 27. В. 11. С. 1857-1862.

[18] Звягин И.П., Курова И.А., Ормонт Н.Н. // ФТП. 1993. T. 27. B. 10. C. $1707-1712$. 